\title{
Buoyant Density Fractionation of Small Extracellular Vesicle Sub-populations Derived from Mammalian Cells \\ Morayma M. Temoche-Diaz ${ }^{1}$, Matthew J. Shurtleff ${ }^{1,2}$ and Randy Schekman², *
}

\author{
${ }^{1}$ Department of Plant and Microbial Biology, University of California, Berkeley, United States; \\ ${ }^{2}$ Department of Molecular and Cellular Biology, Howard Hughes Medical Institute, University of \\ California Berkeley, Berkeley, United States \\ *For correspondence: schekman@berkeley.edu
}

[Abstract] Small extracellular vesicles (sEVs) encompass a variety of distinct vesicles that are secreted to the extracellular space. Many methodologies currently used for EV isolation (e.g., differential ultracentrifugation concluding in a high-speed pellet, precipitation by macromolecular crowding agents or size excusion chromatography-SEC) do not fractionate distinct sEV sub-populations. Samples obtained by the aforementioned methods are usually used for characterization and physiological studies. However the fraction that contains the molecule of interest or is the carrier of a specific activity is unknown. Therefore isolating distinct SEV sub-populations is critical to understand EV function. The goal of this procedure is to purify distinct SEV sub-populations based on slight differences in their buoyant density. Moreover, this technique also allows sEVs purification from vesicle-free RNA-protein complexes co-isolating in the high-speed pellet or by the use of crowding agents. This protocol describes cultivation of mammalian cells for SEV collection, sEV sedimentation, buoyant density fractionation of SEV subpopulations and immunoblots for SEV markers. This protocol can be used to fractionate distinct sEV sub-populations produced by a variety of mammalian cells.

Keywords: Extracellular vesicles, Differential ultracentrifugation, Buoyant density, Exosomes, RNAprotein complexes, OptiPrep

[Background] Small extracellular vesicles (sEVs) are released by virtually all mammalian cells. They have been proposed to play a variety of roles ranging from immunity to cancer metastasis (Pegtel et al., 2010; Mittelbrunn et al., 2011; Montecalvo et al., 2012; Fong et al., 2015; Dickman et al., 2017). Most of the current methodologies used to isolate SEVs however do not distinguish among different SEV subpopulation nor do they purify sEVs from co-isolating protein and RNA-protein complexes (Temoche-Diaz et al., 2019; Kowal et al., 2016; Willms et al., 2016; Jeppesen et al., 2019). Therefore the sedimentable fraction or specific vesicle species that promotes a particular physiological response remains unknown (Shurtleff et al., 2018). A methodology that allows purification of sEVs away from contaminants and fractionation of distinct SEV sub-populations is of broad utility. The procedure explained below uses differential ultracentrifugation followed by buoyant density flotation to allow: 1) Purification of particles associated with a lipidic membrane (sEVs) from non-vesicular particulate material and 2) Fractionation of distinct SEV sub-populations based on slight differences in their buoyant densities. The purified sEV fractions are of suitable purity for use in physiological and/or characterization experiments. 


\section{Materials and Reagents}

1. $15 \mathrm{~cm}$ dishes (Tissue Culture Dish) (Corning, Falcon, catalog number: 08-772-6)

2. Transfer pipettes (Fisherbrand, catalog number: 13-711-7M)

3. Syringe $3 \mathrm{ml}(\mathrm{BD}$, catalog number: 309657$)$

4. Syringe $10 \mathrm{ml}$ (BD, catalog number: 302995)

5. Stainless steel 304 syringe needle (Sigma, catalog number: Z117021-1EA)

6. PrecisionGlide Needle 22G (BD, catalog number: 305159)

7. Immbilion-P PVDF membrane (Millipore Sigma, catalog number: IPVH10010)

8. $50 \mathrm{ml}$ conical tube

9. Open-Top Thinwall Ultra-Clear Tube ( $38.5 \mathrm{ml}), 25 \times 89 \mathrm{~mm}$ (Beckman Coulter, catalog number: 344058)

Note: On text "38.5 ml ultra-clear tube".

10. Open-Top Thinwall Ultra-Clear Tube (13.2 ml), 14 x 89 mm (Beckman Coulter, catalog number: 344059)

Note: On text "13.2ml ultra-clear tube".

11. 4-20\% Criteron Tris-HCl Protein Gel, 26 well (Bio-Rad, catalog number: 3450034)

12. OptiPrep (Sigma, catalog number: D1556-250ml)

13. Sucrose (Fisher Chemical, catalog number: S5-3)

14. HEPES (Sigma, catalog number: $\mathrm{H} 4034-1 \mathrm{Kg}$ )

15. Sodium chloride (Fisher Chemical, catalog number: S271-3)

16. Fetal bovine serum (FBS) (VWR, catalog number: 89510-194)

17. FBS exo-depleted (System Biosciences, catalog number: EXO-FBS-250A-1)

18. RPMI + Glutamax (Gibco, catalog number: 10566-016)

19. Bovine serum albumin (BSA) (Sigma, catalog number: A3294-100G)

20. Antibodies

CD9 (Cell Signaling Technology, catalog number: 13174S)

MFG-E8 (R\&D Systems, catalog number: MAB2767)

ITGA3 (Abcam, catalog number: ab190731)

CD63 (Fisher Scientific, catalog number: BDB556019)

Dicer (Santa Cruz, catalog number: sc30226)

Flot-2 (BD Biosciences, catalog number: 610383)

IgG-anti rabbit HRP linked (Sigma Millipore, catalog number: GENA934-1ml)

IgG-anti rabbit HRP linked (Sigma Millipore, catalog number: NXA931-1ml)

21. Dithiothreitol (DTT) (Goldbio, catalog number: DTT25)

22. Sodium dodecyl sulfate (SDS) (J.T. Baker, catalog number: 4095-02)

23. Tween-20 (Sigma, catalog number: P7949-500ml)

24. Tris-buffered saline (TBS, pH 7.6)

25. Bromophenol-blue (Bio-Rad, catalog number: 161-0404) 
26. Glycerol (AMRESCO, catalog number: M152-4L)

27. Glycine

28. Methanol (Fisher Chemical, catalog number: A452-4)

29. Mammalian cell culture media (see Recipes)

Cell culture growing medium

Exosome-depleted growing medium

30. Stock solutions (see Recipes)

$1 \mathrm{M}$ HEPES $\mathrm{pH} 7.4$

Concentrated OptiPrep buffer

1 M DTT

$1 \mathrm{M}$ Tris $\mathrm{pH} 6.8$

4x Laemmli buffer

4x Laemmli buffer no DTT

10x Transfer buffer

OptiPrep working solution

31. Buffer solutions (see Recipes)

EV buffer

Sucrose cushion

Concentrated sucrose cushion

OptiPrep working solutions 25\%, 20\%, 15\%, 10\%, 5\%

TBS-T

\section{Equipment}

1. Refractometer (Fisher Scientific)

2. Sorvall RC 6+ centrifuge (Thermo Scientific, model: 46910)

3. Fixed angle rotor F14S-6X250y FiberLite (Thermo Scientific, catalog number: 78500)

4. Ultracentrifuge (Beckman Coulter, model: Optima XE-90, catalog number: A94471)

5. Swinging-bucket rotor SW 32 Ti and bucket set (Beckman Coulter, catalog number: 369694)

6. Swinging-bucket rotor SW 41 Ti and bucket set (Beckman Coulter, catalog number: 311362)

7. ChemiDoc MP Imaging Sytem (Bio-Rad Laboratories, model: ChemiDoc MP 10)

\section{Software}

1. ImageLab software $\mathbf{v} 4.0$

2. Image J

3. GraphPad Prism 


\section{Procedure}

A. Cell culture

1. Grow MDA-MB-231 cells in four $15 \mathrm{~cm}$ dishes in $30 \mathrm{ml}$ cell culture growth medium (see Recipe A1) until cells reach $80 \%$ confluency (the cell number at this point is $\sim 16 \times 10^{6}$ cells per dish). Notes:

a. Other model mammalian cells may be used. This methodology has been successful at fractionating sEV sub-populations of several mammalian cells tried to date: HEK-293T, MCF7, MCF10A, MDA-MB-231, PC12 and N2A cells.

b. The surface available for cell growth in these dishes is $151.9 \mathrm{sq} . \mathrm{cm}$. The total volume of cell culture growth medium used for these dishes is $30 \mathrm{ml}$.

2. Expand the four $15 \mathrm{~cm}$ dishes to a total of fourteen $15 \mathrm{~cm}$ dishes each containing an approximate of $4 \times 10^{6}$ cells at moment of seeding in $30 \mathrm{ml}$ of exosome-depleted growth medium (see Recipe A2).

Note: The maximum volume of medium that can be processed in the steps below is $420 \mathrm{ml}$.

3. Incubate cells for $3 \mathrm{~d}$ or until cells reach $80 \%$ confluency. Proceed with medium collection.

Note: Do not allow cells to become overconfluent, we have observed a dramatic decrease in sEVs from overconfluent cultures.

B. Conditioned medium collection and extracellular vesicle sedimentation

1. Collect conditioned medium from fourteen $15 \mathrm{~cm}$ plates by pouring it off in adequate containers. The total amount of conditioned medium collected is $\sim 420 \mathrm{ml}$.

2. Centrifuge the conditioned medium at $1,000 \times \mathrm{g}$ for $15 \mathrm{~min}$ at $4{ }^{\circ} \mathrm{C}$ in a Sorvall $\mathrm{RC} 6+$ centrifuge with fixed angle rotor F14S-6X250y FiberLite (or equivalent) to sediment floating cells (Low speed spin).

3. Immediately after the centrifuge stops, gently pour the supernatant into a new container. Be careful not to disturb the pellet.

4. Centrifuge the supernatant at $10,000 \times \mathrm{g}$ for $15 \mathrm{~min}$ at $4{ }^{\circ} \mathrm{C}$ in a Sorvall $\mathrm{RC} 6+$ centrifuge with fixed angle rotor F14S-6X250y FiberLite to sediment cellular debris and large extracellular vesicles (Medium speed spin).

5. Immediately after the centrifuge stops, gently pour the supernatant into a new container. Be careful not to disturb the pellet.

6. Add $32 \mathrm{ml}$ of the collected supernatant into a single $38.5 \mathrm{ml}$ ultra-clear tube. Repeat this step 5 times to fill a total of six $38.5 \mathrm{ml}$ ultra-clear tubes.

Note: This step will consume $\sim 200 \mathrm{ml}$ of conditioned medium. Save the remaining $\sim 220$ at $4{ }^{\circ} \mathrm{C}$ for a second round of ultracentrifugation (Step B11).

7. Attach the stainless steel 304 needle to a $10 \mathrm{ml}$ syringe. Fill the $10 \mathrm{ml}$ syringe with sucrose cushion (see Recipe C2).

8. Quickly introduce the stainless steel needle into the conditioned medium-filled $38.5 \mathrm{ml}$ ultra- 
clear tube until it reaches the bottom of the tube. Add $2 \mathrm{ml}$ of sucrose cushion and remove the stainless steel needle immediately. Repeat this step 5 times for a total of six $38.5 \mathrm{ml}$ ultra-clear tubes.

9. Centrifuge at $\sim 100,000 \times g(29,500 \mathrm{RPM})$ for $1.5 \mathrm{~h}$ using a SW32 $\mathrm{Ti}$ rotor at $4{ }^{\circ} \mathrm{C}$ at maximum acceleration and brake.

10. Immediately after, aspirate the supernatant from the top to just above the sucrose cushion using an aspirating pipet fixed to a vacuum system. Be careful not to aspirate the interface at the cushion and the conditioned medium (this is where the $\mathrm{SEVs}$ have sedimented). Aspirate until leaving $\sim 4-5 \mathrm{ml}$ of conditioned medium resting on top of the sucrose cushion. Repeat this step 5 times, for a total of six $38.5 \mathrm{ml}$ ultra-clear tubes.

11. Very carefully add the remaining conditioned medium (from Step B6) to each $38.5 \mathrm{ml}$ ultra-clear tube. Do so by using transfer pipettes (see materials) and adding the conditioned medium very slowly and smoothly along the tube wall. Disturbance of the sucrose cushion must be avoided. Any fast pouring can disturb the sucrose cushion.

12. Repeat Steps B9 and B10.

13. Using a $1 \mathrm{ml}$ micropipette carefully collect and discard $\sim 2-3 \mathrm{ml}$ of the $\sim 4-5 \mathrm{ml}$ remaining on top of the sucrose cushion after aspiration. Do so until there is $\sim 2 \mathrm{ml}$ of conditioned medium remaining on top of the sucrose cushion.

Note: For this step, the use of a $1 \mathrm{ml}$ micropipette is recommended over vacuum aspiration. Using a $1 \mathrm{ml}$ micropipette at this step allows a more controlled/accurate medium collection.

14. Collect the $\sim 2 \mathrm{ml}$ of remaining conditioned medium, plus the top-most $1 \mathrm{ml}$ of sucrose cushion and save the $3 \mathrm{ml}$ into a $50 \mathrm{ml}$ conical tube. Repeat this step 5 times with the 5 remaining tubes and pool them together in a single $50 \mathrm{ml}$ conical tube (final volume $\sim 18 \mathrm{ml}$ ).

15. Measure the sucrose concentration of the solution from Step B14 by using a refractometer. Make sure the concentration does not exceed $21 \%$ sucrose $(\mathrm{w} / \mathrm{v})$. If the concentration exceeds $21 \%$ sucrose dilute with EV buffer. Generally an adequate sucrose concentration ranges from 15 to $20 \%$.

Note: If the sucrose concentration from B15 exceeds $21 \%$ sucrose $(\mathrm{W} / \mathrm{V})$, sEVs will not sediment in Step B18 and instead they will equilibrate throughout the $13.2 \mathrm{ml}$ ultra-clear tubes.

16. Fill two $13.2 \mathrm{ml}$ ultra-clear tubes with the collected sEVs from Step B15. Add $\sim 9-11 \mathrm{ml}$ per tube.

17. Add $1 \mathrm{ml}$ of sucrose cushion on the bottom of each $13.2 \mathrm{ml}$ ultra-clear tube as in Step B8.

18. Centrifuge at $\sim 130,000 \times g(32,500$ RPM $)$ for $15 \mathrm{~h}$ using a SW41 Ti rotor at $4{ }^{\circ} \mathrm{C}$ at maximum acceleration and brake.

19. Immediately after, use a vacuum system to aspirate the supernatant from top to bottom. Be careful not to aspirate the layer in between the cushion and the conditioned medium (this is where the sEVs have sedimented). Aspirate until leaving $\sim 2 \mathrm{ml}$ of conditioned medium resting on top of the sucrose cushion. Repeat this step 1 time with the remaining $13.2 \mathrm{ml}$ ultra-clear tube.

20. Using a $1 \mathrm{ml}$ micropipette collect and discard an extra $\sim 1.2 \mathrm{ml}$ of conditioned medium remaining 
on top. Repeat this step 1 time with the remaining $13.2 \mathrm{ml}$ ultra-clear tube.

Note: For this final step, the use of a $1 \mathrm{ml}$ micropipette is recommended over vacuum aspiration to have a more controlled/accurate collection of medium.

21. Collect the remaining content of the $13.2 \mathrm{ml}$ ultra-clear tube. This includes $800 \mu \mathrm{l}$ of conditioned medium remaining on top of the sucrose cushion, plus $1 \mathrm{ml}$ of the sucrose cushion. Pool the content of the two $13.2 \mathrm{ml}$ ultra-clear tubes together into a $50 \mathrm{ml}$ conical tube (the total volume at this step is $\sim 3.6 \mathrm{ml})$.

22. Add $1.9 \mathrm{ml}$ of concentrated sucrose cushion (see Recipe C2) and mix properly.

23. Use the refractometer to measure sucrose concentration. The sucrose concentration after this step is generally higher than $42 \%$ sucrose $(\mathrm{w} / \mathrm{v})$. Values equal or higher than $42 \%$ are adequate. Note: If the sucrose concentration does not exceed $42 \%$ add more concentrated sucrose cushion until it is equal or exceeds this value. If the concentration is lower, the OptiPrep layer from Step C3 will have higher density and sink, impeding the proper linear gradient formation.

24. Save $10 \%$ from B23 $(500 \mu \mathrm{l})$ to use as " $100,000 \times \mathrm{g}$ pellet" in Procedures D and E.

C. Extracellular vesicle flotation into an OptiPrep linear gradient and fraction collection

1. Add the remaining $5 \mathrm{ml}$ from Step B23 to the bottom of a $13.2 \mathrm{ml}$ ultra-clear tube by using a $1 \mathrm{ml}$ micropipette.

2. Attach the $22 \mathrm{G}$ needle to a $3 \mathrm{ml}$ syringe. Then fill the $3 \mathrm{ml}$ syringe with OptiPrep solution $25 \%$ (see Recipe C4).

3. Extend the $22 \mathrm{G}$ needle to the top-most layer in the $13.2 \mathrm{ml}$ ultra-clear tube. Once the $22 \mathrm{G}$ needle is within a few millimeters from the top layer, very slowly and carefully add $1.5 \mathrm{ml}$ of OptiPrep solution $25 \%$.

Note: This step and Step C4 require extreme caution. Adding the OptiPrep layers must be done very slowly and smoothly. Failure to do so can cause the layers to mix and subsequent failure of gradient formation.

4. Repeat Step C3 with the OptiPrep solutions 20\%, 15\%, 10\% and 5\% (see Recipe C4) in this respective order.

5. Centrifuge at $\sim 160,000 \times g(36,000 \mathrm{RPM})$ for $15 \mathrm{~h}$ using a SW41 $\mathrm{Ti}$ rotor at $4{ }^{\circ} \mathrm{C}$ at minimum acceleration and NO brake.

Note: It is important to have no brake during deceleration. Having the brake on can cause disruption of the gradient and mixture of $s E V$ sub-populations.

6. Once stopped, collect $400 \mu \mathrm{l}$ fractions from top to bottom using of a $1 \mathrm{ml}$ micropipette. A schematic summarizing Steps B1 to C6 is shown in Figure 1.

Note: Two different SEV sub-populations can be observed against a black background and with the appropriate lighting (application of an artificial or natural source of light can aid visualization). The 2 distinct sEV sub-populations will appear as 2 separate white bands contrasting with the black background. 


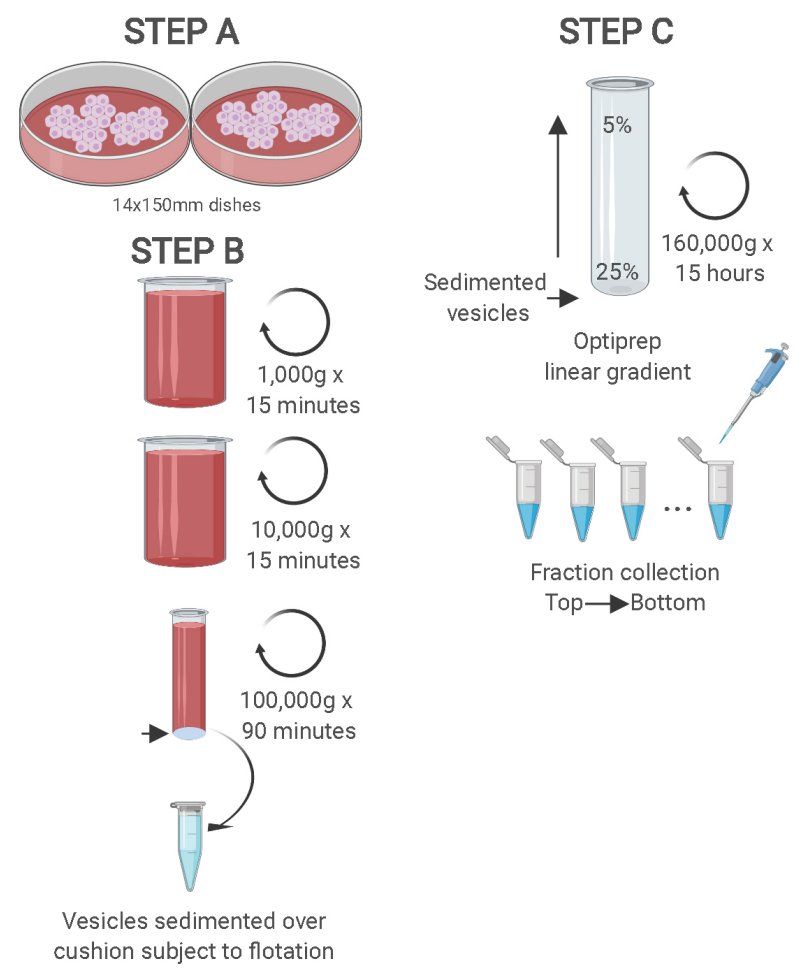

Figure 1. Schematic showing the two-step purification methodology. Differential ultracentrifugation is followed by buoyant density flotation in a linear OptiPrep gradient. Figure taken from Temoche-Diaz et al. (2019).

7. Mix each $400 \mu$ fraction by the use of a vortexer and measure their refractive indices to confirm linearity. The formation of an OptiPrep linear gradient is required for the success of this protocol in order to fractionate sEVs with slight differences in their densities. Disruption of linearity would cause failure of an adequate sEV fractionation.

Notes:

a. Linearity is often observed from fraction 1 to 25 . The remaining 6 bottom fractions have little to no change in their density as the fraction number increases.

b. The low density sEV fractions generally range from fractions 9-11. The high density sEV fractions generally float to fractions 15-17. However there can be slight variations in different linear gradients and the fraction number where SEVs equilibrate can slightly change. Therefore it is recommended to note the refractive index of each fraction and match this refractive index to $S E V$ presence (by immunoblots, Procedure E below). Once the density corresponding to SEV sub-populations has been empirically determined in this way, only refractive index measurements are necessary in future experiments to identify $s E V$ containing fractions.

8. Fractions can now be mixed with $4 x$ Laemmli buffer (see Recipe B5) or be concentrated as in Procedure D.

Note: The detection of certain sEV markers can be done successfully without the need for 
concentrating by additional ultracentrifugation, however concentration is recommended to detect most of the sEV markers. Antibodies that show sufficient sensitivity to detect marker proteins without concentration in our experience are anti-CD9, anti-ITGA3 and anti-dicer.

D. Concentration of fractions

1. Mix each fraction with $10 \mathrm{ml}$ of EV buffer.

2. Centrifuge at $\sim 130,000 \times g(32,500 \mathrm{RPM})$ for $1.5 \mathrm{~h}$ using a SW $41 \mathrm{Ti}$ rotor at $4{ }^{\circ} \mathrm{C}$ at maximum acceleration and deceleration.

3. Decant the supernatant.

4. Add 50-100 $\mu \mathrm{l}$ of $1 \mathrm{x}$ Laemmli buffer. Pipette up and down 3-7 times. Incubate for $10 \mathrm{~min}$ at room temperature.

Note: If the detection of CD63 is desired, resuspend as specified above in 1x Laemmli buffer without DTT. The addition of reducing reagents causes failure of the detection of CD63 with the antibody BDB556019.

5. Collect the material and freeze at $-20^{\circ} \mathrm{C}$ or use immediately.

E. Immunoblot

1. Incubate samples at $95^{\circ} \mathrm{C}$ for $5 \mathrm{~min}$.

2. Load $10 \mathrm{ul}$ of samples per lane in a $4-20 \%$ Criteron 26 -well gel. Note: Pooling samples 1-3; 4, 5; 23-25; 26-28 and 29, 30 is advised in order to fit all fractions in the same gel. The aforementioned fractions generally do not contain sEVs in our observations (although we cannot exclude variation in other cell lines).

3. Run at constant voltage, $150 \mathrm{~V}$, for $1.5 \mathrm{~h}$.

4. Transfer into a PVDF membrane with constant amps, $0.4 \mathrm{~A}$, for $2.5 \mathrm{~h}$.

5. Block membrane(s) for $1 \mathrm{~h}$ with $5 \%$ BSA in TBS-T (see Recipes C5).

6. Incubate membrane(s) with the desired primary antibodies overnight in the cold room $\left(4{ }^{\circ} \mathrm{C}\right)$. Working dilution for anti-CD9 is 1:3,000. All other antibodies 1:1,000.

7. Wash 3 times with TBS-T (see Recipes C5) for 8 min each wash.

8. Incubate with horseradish peroxidase (HRP) conjugated secondary antibody (anti-mouse or anti-rabbit) for $1 \mathrm{~h}$ at room temperature. Working dilutions 1:10,000.

9. Wash 3 times with TBS-T (see Recipes C5) for 8 min each wash.

10. Add the HRP substrate following the manufacturer specifications. Develop using Chemidoc Imaging System.

Note: We regularly use Pierce ECL Plus western blotting substrate (Thermo Scientific) though similar chemiluminescent substrates may be substituted.

\section{Data analysis}

1. Export the .tif images using the ImageLab software v4.0. 
2. Open images in ImageJ, use a rectangle tool to highlight bands and quantify the intensity of bands by choosing Analyze $\rightarrow$ Gels $\rightarrow$ Label peaks.

Note: For a detailed explanation on how to analyze immunoblot bands by ImageJ, please access to this link: https://www.sybil-fp7.eu/node/95.

3. Use GraphPad Prism or preferred program to plot the sEV markers distributions (Figure 2B).

4. Collide Stack and align images using Adobe Illustrator or preferred program (Figure 2A).

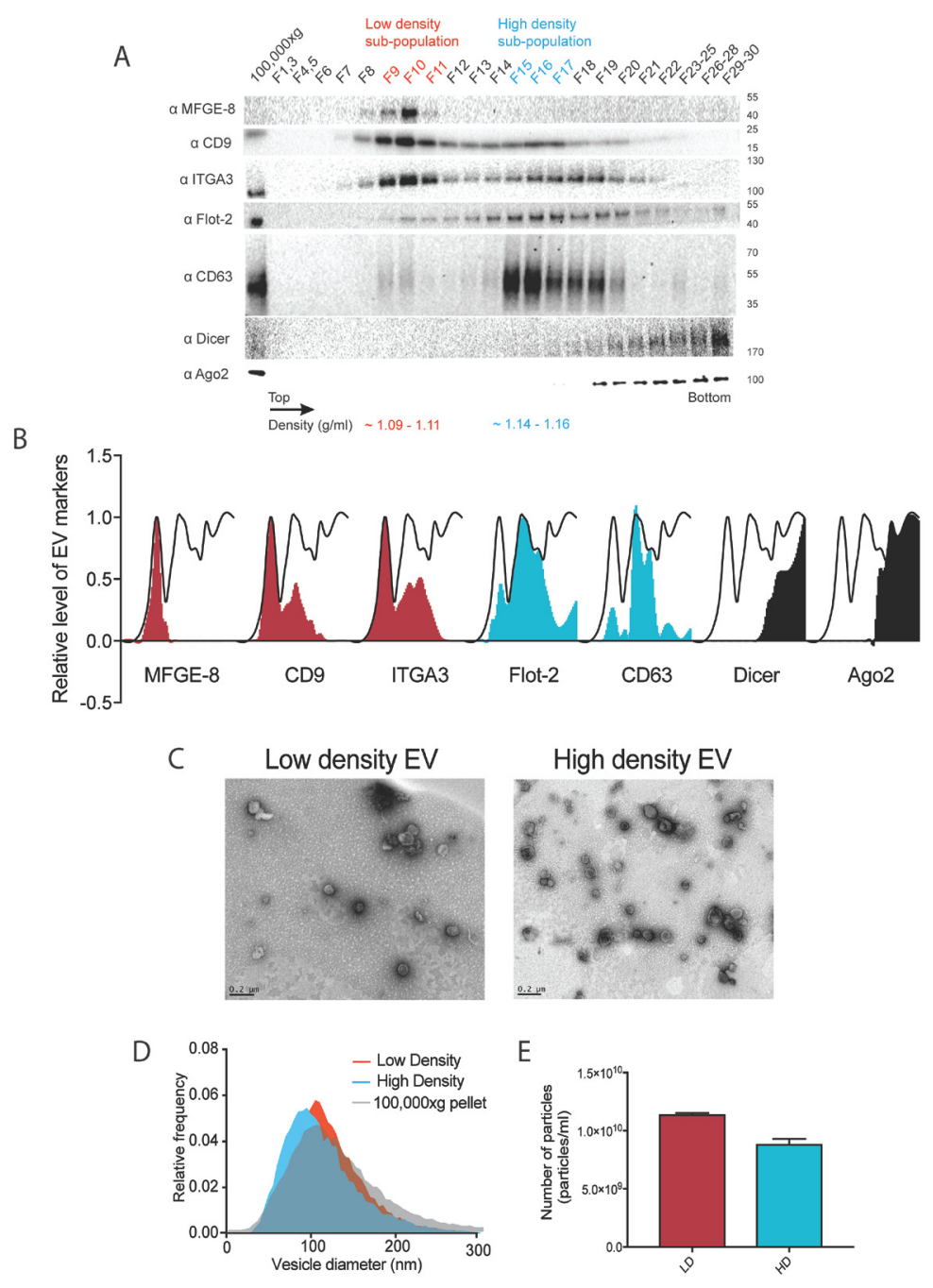

Figure 2. Two biochemically distinct sEV sub-populations are released by MDA-MB-231. A. Representative image of immunoblots for SEV markers across the gradient. B. Quantification of the intensity of each sEV marker across the gradient. Black line delineates the maximum signal across the gradient showing three distinctive areas. The first, second and third peak represent the low density EVs, high density EVs and non vesicular protein-RNA complexes respectively. In order to follow the International Society of Extracellular Vesicle (ISEV) guidelines (Thery et al., 2018), electron microscope images and nanoparticle analysis are also shown in C, D and E. C. Representative electron micrographs of negative stained high density and lowdensity EV samples. D. Nanoparticle tracking analysis showing the size distribution of the high- 
density and low-density sub-populations. The high-speed pellet is also shown. E. Quantification of the particle number per sEV subpopulation using Nanoparticle tracking analysis. Data plotted are from two independent experiments; error bars represent standard deviation from independent samples. Figure taken from Temoche-Diaz et al. (2019)

\section{$\underline{\text { Notes }}$}

This protocol assumes the users have knowledge of how to perform immunoblots and analyze the data.

\section{$\underline{\text { Recipes }}$}

A. Mammalian cell culture media

1. Cell culture growing medium

Add $10 \%$ FBS to DMEM-Glutamax

2. Exosome-depleted growing medium

Add $10 \%$ exo-depleted FBS to DMEM-Glutamax

B. Stock solutions

1. $1 \mathrm{M} \mathrm{HEPES} \mathrm{pH} 7.4(500 \mathrm{ml})$

a. Dissolve $119.2 \mathrm{~g}$ of HEPES in $400 \mathrm{ml}$ of $\mathrm{ddH}_{2} \mathrm{O}$

b. Add $10 \mathrm{~N} \mathrm{NaOH}$ until $\mathrm{pH}$ reaches 7.4

c. Add $\mathrm{ddH}_{2} \mathrm{O}$ to $500 \mathrm{ml}$

d. Store at $4{ }^{\circ} \mathrm{C}$

2. Concentrated OptiPrep buffer $(100 \mathrm{ml})$
a. Dissolve $0.85 \mathrm{~g}$ of $\mathrm{NaCl}$ in $70 \mathrm{ml}$ of $\mathrm{ddH}_{2} \mathrm{O}$
b. Add $6 \mathrm{ml}$ of $1 \mathrm{M}$ HEPES $\mathrm{pH} 7.4$
c. Add $\mathrm{ddH}_{2} \mathrm{O}$ to $100 \mathrm{ml}$

3. $1 \mathrm{M} \mathrm{DTT}(10 \mathrm{ml})$
a. Dissolve $1.5 \mathrm{~g}$ of DTT in $6 \mathrm{ml}$ of $\mathrm{ddH}_{2} \mathrm{O}$
b. Add $\mathrm{ddH}_{2} \mathrm{O}$ to $10 \mathrm{ml}$
c. Make $1 \mathrm{ml}$ aliquots
d. Store at $-20^{\circ} \mathrm{C}$

4. $1 \mathrm{M}$ Tris $\mathrm{pH} 6.8(100 \mathrm{ml})$
a. Dissolve $12.1 \mathrm{~g}$ of Tris Base in $80 \mathrm{ml}$ of $\mathrm{ddH}_{2} \mathrm{O}$
b. Adjust $\mathrm{pH}$ with $10 \mathrm{~N} \mathrm{HCl}$ to 6.8
c. Add $\mathrm{ddH}_{2} \mathrm{O}$ to $100 \mathrm{ml}$

5. $4 x$ Laemmli buffer $(20 \mathrm{ml})$

a. Dissolve $1.6 \mathrm{~g}$ of SDS in $6 \mathrm{ml}$ of $\mathrm{ddH}_{2} \mathrm{O}$ 

b. Add $5 \mathrm{ml}$ of $1 \mathrm{M}$ Tris-HCl pH 6.8
c. Add $1.23 \mathrm{~g}$ of DTT. Dissolve
d. Add $8 \mathrm{mg}$ of bromophenol blue
e. Add $8 \mathrm{ml}$ of glycerol
f. Add $\mathrm{ddH}_{2} \mathrm{O}$ to $20 \mathrm{ml}$
g. Make $1 \mathrm{ml}$ aliquots
h. Store at $-20^{\circ} \mathrm{C}$

6. $4 \mathrm{x}$ Laemmli buffer no DTT $(20 \mathrm{ml})$

Follow as Recipe B5, but do not include DTT.

7. 10x Transfer buffer ( $1 \mathrm{~L})$
a. Dissolve $114.2 \mathrm{~g}$ of glycine in $400 \mathrm{ml}$ of $\mathrm{ddH}_{2} \mathrm{O}$
b. Add $24.2 \mathrm{~g}$ of Tris-base. Dissolve
c. Add $\mathrm{ddH}_{2} \mathrm{O}$ to $1 \mathrm{~L}$
d. Store at $4{ }^{\circ} \mathrm{C}$

8. OptiPrep working solution
a. Mix $10 \mathrm{ml}$ of OptiPrep with $2 \mathrm{ml}$ of concentrated OptiPrep buffer
b. Store at $4{ }^{\circ} \mathrm{C}$

C. Buffers/Solutions

1. EV buffer $(100 \mathrm{ml})$
a. Dissolve $0.85 \mathrm{~g}$ of $\mathrm{NaCl}$ in $70 \mathrm{ml}$ of $\mathrm{ddH}_{2} \mathrm{O}$
b. Add $1 \mathrm{ml}$ of $1 \mathrm{M}$ HEPES $\mathrm{pH} 7.4$
c. Add $\mathrm{ddH}_{2} \mathrm{O}$ to $100 \mathrm{ml}$
d. Store at $4{ }^{\circ} \mathrm{C}$

2. Sucrose cushion $(40 \mathrm{ml})$
a. Add $27 \mathrm{~g}$ of sucrose in a $50 \mathrm{ml}$ conical tube
b. Add EV buffer up to $40 \mathrm{ml}$. Dissolve the sucrose
Note: It takes $\sim 10$ min with constant mixing to dissolve the sucrose completely.
c. Measure the refractive index and calculate the sucrose concentration
d. Adjust to $60 \%(\mathrm{w} / \mathrm{v})$ of sucrose by adding more sucrose or diluting with EV buffer Note: Adding $24 \mathrm{~g}$ of sucrose for a $40 \mathrm{ml}$ solution does not yield a $60 \%$ sucrose solution (as measured by refractive index). Therefore it is advised to start step 2a with $27 \mathrm{~g}$ of sucrose instead.
e. Store at $4^{\circ} \mathrm{C}$

3. Concentrated sucrose cushion $(40 \mathrm{ml})$
a. Add $31 \mathrm{~g}$ of sucrose in a $50 \mathrm{ml}$ conical tube
b. Add EV buffer to $40 \mathrm{ml}$. Dissolve the sucrose completely
c. Take the refractive index and calculate the sucrose concentration
Note: This solution will have an approximate $65 \%$ sucrose concentration. 


\section{d. Store at $4{ }^{\circ} \mathrm{C}$}

4. OptiPrep working solutions $(5 \mathrm{ml})$

Follow the Table 1 below to prepare the OptiPrep working solutions.

Table 1. Table showing calculations of different concentrations of OptiPrep working media

\begin{tabular}{lcc}
\hline & OptiPrep Working Solution (ml) & EV buffer $(\mathrm{ml})$ \\
\hline OptiPrep 25\% & 2.5 & 2.5 \\
OptiPrep 20\% & 2 & 3 \\
OptiPrep 15\% & 1.5 & 3.5 \\
OptiPrep 10\% & 1 & 4 \\
OptiPrep 5\% & 0.5 & 4.5 \\
\hline
\end{tabular}

5. TBS-T

$0.1 \%$ Tween $20(\mathrm{v} / \mathrm{v})$ in $1 \mathrm{x}$ TBS

\section{Acknowledgments}

We would like to thank current and former Schekman lab members who provided technical advice in the development of this protocol. We also acknowledge the Howard Hughes Medical Institute for funding. This protocol has been adapted from Temoche-Diaz et al., 2019.

\section{Competing interests}

The authors declare no competing interests.

\section{$\underline{\text { References }}$}

1. Dickman, C. T., Lawson, J., Jabalee, J., MacLellan, S. A., LePard, N. E., Bennewith, K. L. and Garnis, C. (2017). Selective extracellular vesicle exclusion of miR-142-3p by oral cancer cells promotes both internal and extracellular malignant phenotypes. Oncotarget 8(9): 15252-15266.

2. Fong, M. Y., Zhou, W., Liu, L., Alontaga, A. Y., Chandra, M., Ashby, J., Chow, A., O'Connor, S. T., Li, S., Chin, A. R., Somlo, G., Palomares, M., Li, Z., Tremblay, J. R., Tsuyada, A., Sun, G., Reid, M. A., Wu, X., Swiderski, P., Ren, X., Shi, Y., Kong, M., Zhong, W., Chen, Y. and Wang, S. E. (2015). Breast-cancer-secreted miR-122 reprograms glucose metabolism in premetastatic niche to promote metastasis. Nat Cell Biol 17(2): 183-194.

3. Jeppesen, D. K., Fenix, A. M., Franklin, J. L., Higginbotham, J. N., Zhang, Q., Zimmerman, L. J., Liebler, D. C., Ping, J., Liu, Q., Evans, R., Fissell, W. H., Patton, J. G., Rome, L. H., Burnette, 
D. T. and Coffey, R. J. (2019). Reassessment of Exosome Composition. Cell 177(2): 428-445 e418.

4. Kowal, J., Arras, G., Colombo, M., Jouve, M., Morath, J. P., Primdal-Bengtson, B., Dingli, F., Loew, D., Tkach, M. and Thery, C. (2016). Proteomic comparison defines novel markers to characterize heterogeneous populations of extracellular vesicle subtypes. Proc Natl Acad Sci U S A 113(8): E968-977.

5. Mittelbrunn, M., Gutierrez-Vazquez, C., Villarroya-Beltri, C., Gonzalez, S., Sanchez-Cabo, F., Gonzalez, M. A., Bernad, A. and Sanchez-Madrid, F. (2011). Unidirectional transfer of microRNA-loaded exosomes from T cells to antigen-presenting cells. Nat Commun 2: 282.

6. Montecalvo, A., Larregina, A. T., Shufesky, W. J., Stolz, D. B., Sullivan, M. L., Karlsson, J. M., Baty, C. J., Gibson, G. A., Erdos, G., Wang, Z., Milosevic, J., Tkacheva, O. A., Divito, S. J., Jordan, R., Lyons-Weiler, J., Watkins, S. C. and Morelli, A. E. (2012). Mechanism of transfer of functional microRNAs between mouse dendritic cells via exosomes. Blood 119(3): 756-766.

7. Pegtel, D. M., Cosmopoulos, K., Thorley-Lawson, D. A., van Eijndhoven, M. A., Hopmans, E. S., Lindenberg, J. L., de Gruijl, T. D., Wurdinger, T. and Middeldorp, J. M. (2010). Functional delivery of viral miRNAs via exosomes. Proc Natl Acad Sci U S A 107(14): 6328-6333.

8. Shurtleff, M. J., Temoche-Diaz, M. M. and Schekman, R. (2018). Extracellular Vesicles and Cancer: Caveat Lector. Annu Rev Cancer Biol 2(1): 395-411.

9. Thery, C., Witwer, K. W., Aikawa, E., Alcaraz, M. J., Anderson, J. D., Andriantsitohaina, R., Antoniou, A., Arab, T., Archer, F., Atkin-Smith, G. K., et al. (2018). Minimal information for studies of extracellular vesicles 2018 (MISEV2018): a position statement of the International Society for Extracellular Vesicles and update of the MISEV2014 guidelines. $J$ Extracell Vesicles 7(1): 1535750.

10. Temoche-Diaz, M. M., Shurtleff, M. J., Nottingham, R. M., Yao, J., Fadadu, R. P., Lambowitz, A. M. and Schekman, R. (2019). Distinct mechanisms of microRNA sorting into cancer cell-derived extracellular vesicle subtypes. Elife 8: 47544.

11. Willms, E., Johansson, H. J., Mager, I., Lee, Y., Blomberg, K. E., Sadik, M., Alaarg, A., Smith, C. I., Lehtio, J., El Andaloussi, S., Wood, M. J. and Vader, P. (2016). Cells release subpopulations of exosomes with distinct molecular and biological properties. Sci Rep 6: 22519. 